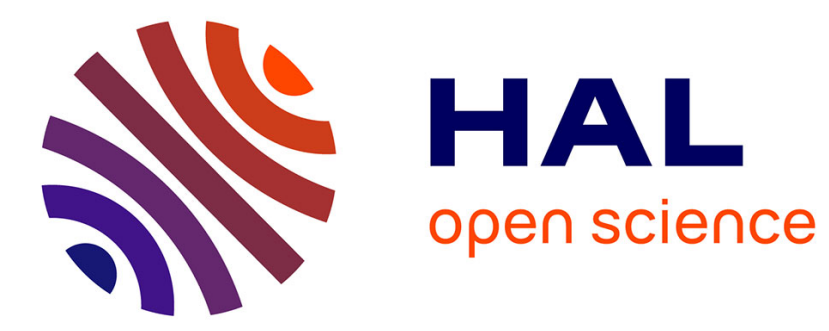

\title{
Artifact Induced by a Transponder During In Vivo Magnetic Resonance Imaging on Horse Brain
}

Arsène Ella, Gilles Gomot, Isabelle Lévy, Claudia Dominici, Hans Adriaensen, Fabrice Reigner, Matthieu Keller, Daniel Guillaume

\section{- To cite this version:}

Arsène Ella, Gilles Gomot, Isabelle Lévy, Claudia Dominici, Hans Adriaensen, et al.. Artifact Induced by a Transponder During In Vivo Magnetic Resonance Imaging on Horse Brain. Journal of Equine Veterinary Science, 2019, 77, pp.63-67. 10.1016/j.jevs.2019.02.025 . hal-02380228

\section{HAL Id: hal-02380228 \\ https://hal.science/hal-02380228}

Submitted on 22 Oct 2021

HAL is a multi-disciplinary open access archive for the deposit and dissemination of scientific research documents, whether they are published or not. The documents may come from teaching and research institutions in France or abroad, or from public or private research centers.
L'archive ouverte pluridisciplinaire HAL, est destinée au dépôt et à la diffusion de documents scientifiques de niveau recherche, publiés ou non, émanant des établissements d'enseignement et de recherche français ou étrangers, des laboratoires publics ou privés.

\section{(ㅇ)(1) $\$$}

Distributed under a Creative Commons Attribution - NonCommerciall 4.0 International 
9 1/ Physiologie de la Reproduction et des Comportements, INRA/CNRS/Université de

Tours/IFCE, Nouzilly, France

2/ MRC Cognition and Brain Science, University of Cambridge, UK

4/INRA, UEPAO, Nouzilly, France

Short title: Artefact induced by a transponder in MRI

Keywords: horse; brain; magnetic resonance imaging; susceptibility artefact

*Corresponding author: Matthieu.Keller@inra.fr 


\section{Summary}

Magnetic Resonance Imaging (MRI) is now widely used in equine veterinary practice. However, the mandatory European legislation regarding horse identification imposes the implantation of a transponder within the fatty tissue of the neck cervical ligament. While performing brain MRI for scientific purposes in ponies, we faced artifacts produced by such transponder and reported here this problem. Indeed, pony mares were anesthetized for 2 hours and placed, bedded on their back, in a 3 Tesla MRI scanner. A 4-element flexible antenna positioned around the head was used. Three MRI sequences were performed on each animal: 3D T1, 3D T2 and 2D T1. The anesthesia allowed the acquisition of MRI for 2 hours. The images for the 3 MRI sequences for each pony exhibited great quality on all of the anterior parts of the brain but began to become distorted posteriorly to the pineal pituitary axis and completely disappeared at the level of the cerebellum. To find the origin of the artifact, the transponder used for the identification of the animal was inserted in an inert gel and imaged in the same conditions as the ponies. The images obtained looked similar to the observed artifact. Our study thus advocates for the further exploration of such kind of artifact when using 3T MRI in brain imaging in horses. 


\section{Introduction}

Magnetic Resonance Imaging (MRI) allows the visualization of soft tissues with an accuracy that is dependent upon the strength of the magnetic field applied. At the brain level, MRI approaches are not only of interest for clinical diagnostics but also for fundamental research. In equine medicine, the use of MRI is strongly developed for the diagnosis of lameness using low field MRI. By contrast, the use of MRI for other organs such as the brain has been quite poorly described. A few publications have described the standard neuroanatomical organization of the horse brain following MRI imaging [1, 2, 3, 4, 5, 6]. For clinical purposes, MRI studies have been used only in few, serious pathological cases, resulting in the publication of clinical case descriptions (for example [7, 8, 9]). Manso-Diaz et al. [10] described 65 horses with neurological disorders and 14 with sinonasal disorders. To date, no study has been performed to explore fundamental regulations of brain physiology using MRI. However, MRI would make it possible to explore and better understand several fundamental biological characteristics of horses, for example, those related to season (reproduction, etc. [11]), to cognitive function [12], or to behavior, especially in relation to stress and welfare [13].

While performing brain anatomical MRI acquisition on anaesthetized horses, we faced the problem of an artifact on MRI images, probably due to the presence of the magnetic transponder used for the identification of animals. Indeed, in Europe, the identification of animals, especially horses, has become widely recognized as important in relation to animal welfare or sanitary issues. In some European countries, the identification of horses is now performed through the mandatory insertion of a magnetic transponder within the fatty tissue of the cervical ligament in the middle of the neck in the area of the nucal ligament (UE 2015/262). A transponder is an implantable electronic device, working as a passive identification method that contains metallic components. Performing magnetic resonance imaging (MRI) in the presence of such metallic device raises concerns due to local signal increase, signal void or distortion (susceptibility artifact) on MR images. Knowing that such distortion can profoundly affect the quality of MRI images, we document here this problem in horses, as previoulsy reported in other species such as dogs for example [14]. 
Materials and methods

\section{Animals}

This experiment was performed in accordance with the National Animal Ethics Requirements (French Ministry of Agriculture). Our experimental MRI platform and horse stable received a veterinary agreement under reference E37-175-2, and our protocol received the authorization of the regional committee for ethics on animal experimentation under the reference 2016100713288243 (Comité d'Ethique en Expérimentation Animale Centre Val-deLoire). Animals were subjected to a clinical examination before the start of the protocol.

For this study, two Welsh pony mares were used (A: $198 \mathrm{~kg}, 2$ years old and B: $198 \mathrm{~kg}, 4$ years old). These mares are identified in our experimental herd with both an earring, which is classically used for bovines, and with a transponder. The earring is commercialized by AllFlex Europe SA (Vitré, France). The use of a transponder is a legal obligation in the European Community (Europe 2015). It was intramuscularly injected in the upper part of the horse necks approximately 10 to $15 \mathrm{~cm}$ behind the head. This injection was performed by a veterinarian before the end of the birth year of the foal. In our experimental ponies, the transponder is a Backhome ${ }^{\circledR}$ Biotec Slim Transponder, which can be read at $25 \mathrm{~cm}$ and which is only $2 \mathrm{~mm}$ in diameter and $10 \mathrm{~mm}$ in length.

\section{Anesthesia}

One hour before the induction of anesthesia, the horse was sedated in order to limit stress before and during the sleeping phase. Sedation was induced with an intramuscular injection of acepromazine $0.1 \mathrm{mg} / \mathrm{kg}$ (Calmivet ${ }^{\circ}$ CEVA Santé Animale, Libourne, France). An intravenous catheter was then placed in the jugular vein. After that, $0.05 \mathrm{mg} / \mathrm{kg}(1 \mathrm{~mL})$ of romifidine hydrochloride (Sédivet ${ }^{\circledR}$ Boehringer-Ingelheim Vetmedica Inc.) was injected iv as 
a premedication. Five minutes afterward, $2.5 \mathrm{mg} / \mathrm{kg}(5 \mathrm{~mL})$ ketamine hydrochloride (Imalgène ${ }^{\circledR}$ Boehringer-Ingelheim Vetmedica Inc.) and $0.08 \mathrm{mg} / \mathrm{kg}(1 \mathrm{~mL})$ diazepam (Valium ${ }^{\circledR}$ ROCHE, Boulogne-Billancourt, France) were injected via the catheter to induce anaesthesia. The animal was bedded in dorsal recumbency, and endotracheal intubation was performed. The anesthesia was maintained with a mixed gas of $2 \%$ isoflurane, $49 \%$ oxygen and $49 \%$ air. Just before the imaging session, a new injection of $5 \mathrm{~mL}$ of Imalgène ${ }^{\circledR}$ and $2 \mathrm{~mL}$ of Valium ${ }^{\circledR}$ were performed. During the imaging session, the mare was perfused with $5 \mathrm{~L}$ of Ringer's solution with $50 \mathrm{~mL}$ of heptaminol acefylline added (Vétécardiol®. Boehringer-Ingelheim, Vetmedica Inc. MSD, Beaucouze, France). A urinary Foley probe was inserted in the bladder to evacuate the urine into a receptacle. The anesthesia was monitored for 3 hours, this duration also including the time for the animal positioning. After the anesthesia, during the reawakening, $5 \mathrm{~L}$ of Ringer's solution was perfused; for additional care, a packet of Twydil-Protect-Plus® was administered per os (combination of antioxidant vitamins and specific antioxidants, PavescoAG, Basel, Switzerland).

After endotracheal intubation, the pony mare was manually lifted and bedded on an MRI table that was covered with a medical mattress specially made to avoid compression (SARL Kohlas, Venissieux, France). The pony mare was bedded on her back for the purposes of animal comfort and to facilitate the introduction of the head into the bore magnet of the MRI. The mare was wedged by cushions and strapped in this position. The head was covered by a radio frequency $(\mathrm{RF})$ coil. In this position, the head was placed close to the center of the bore magnet.

\section{MRI}



device, with a strong magnetic field, ensures high image quality of the brain. The size of the bore magnet is sufficient to insert the horse's head. In addition, the table is also strong enough to accept small ponies of up to $200 \mathrm{~kg}$.

A 4-element flexible coil positioned around the head was used. Three MRI sequences were performed on each animal and were set as follows:

- a 3D T1 sequence of "magnetization prepared rapid acquisition gradient echo" (MPRAGE); with the following parameters: repetition time $(\mathrm{TR})=2500 \mathrm{~ms}$, echo time $(\mathrm{TE})=2.93 \mathrm{~ms}$, inversion time $(\mathrm{TI})=900 \mathrm{~ms}$, flip angle $=12$ degrees, field-of-view (FOV): $260 \mathrm{~mm}^{2}$, and matrix: 3842; bandwidth: $150 \mathrm{~Hz} / \mathrm{Px}$, slice thickness: $0.7 \mathrm{~mm}$, and integrated parallel acquisition technique (iPAT) of 2; number of excitations (NEX): 3 , acquisition time: $33 \mathrm{~min} 24 \mathrm{sec}$, and voxel size: $0.7 \times 0.7 \times 0.7 \mathrm{~mm}^{3}$.

- a 3D T2 sequence of sampling perfection with application-optimized contrasts (SPACE); with the following parameters: $\mathrm{TR}=4000 \mathrm{~ms}, \mathrm{TE}=415 \mathrm{~ms}$, TI $=380 \mathrm{~ms}$, FOV: 180 mm², and matrix: 2562; bandwidth: $349 \mathrm{~Hz} / \mathrm{Px}$, turbo factor: 309 , slice thickness: $0.7 \mathrm{~mm}$, and iPAT of 2; NEX: 2.5, acquisition time: $34 \mathrm{~min} 42 \mathrm{sec}$, and voxel size: 0.7 x 0.7 x 0.7 $\mathrm{mm}^{3}$

- a 2D T1 Spin Echo (SE); with the following parameters: TR $=500 \mathrm{~ms}$, TE $=8.4 \mathrm{~ms}$, FOV: $220 \mathrm{~mm}^{2}$, and matrix: 2562; bandwidth: $201 \mathrm{~Hz} / \mathrm{Px}$, slice thickness: $4 \mathrm{~mm}$, and NEX: 1; concatenations: 2, acquisition time: $3 \mathrm{~min} 45 \mathrm{sec}$, and voxel size: 0.9 x 0.9 × 4 $\mathrm{mm}^{3}$.

These sequences were chosen to have a high spatial resolution for scientific purposes and were not designed for clinical examination.

\section{Results}


these 2 hours, the horses were transported to their stall and awakened safely. One hour later, they were free in a paddock.

On the MR images, sufficient contrast was obtained between gray matter, white matter and cerebrospinal fluid (figure 1). This makes the visualization of the main cerebral structures such as the hippocampus, the corpus callosum, the caudate-putamen nucleus and the hypothalamus straightforward, as previously reported [5]. These images are of sufficiently high quality to also allow image processing, such as, for example, 3D reconstruction of the brain.

However, when acquiring the images, we noticed the presence of an important artifact on the MRI images. A clear black/white ring can be seen on the limit of the signal loss, suggesting the presence of a metal artifact. In this experiment, we attempted two different echo sequences (gradient echo and spin echo), and they both produced artifacts. Even with the use of the SE sequence which is much less sensitive to susceptibility-induced artifacts, important artifacts were observed on the MRI images (see figure 2). The images were not usable from the hypothalamus and toward the rear, which corresponds to $1 / 3$ of the entire brain (figure 2). The 3D reconstruction of the brain was possible, but the reconstruction was distorted (figure 3).

Two objects can create this artifact: the earring bearing the number of the pony or the transponder bearing its official identification number. To find the origin of the artifact, the earring was inserted in an inert gel and placed in the MRI scanner. The same sequences as the ones used with the ponies were employed. The metal part of this earring is composed of brass, and no artifact was seen. On the other hand, the transponder inserted in the gel created an important artifact comparable to that observed in vivo in the image, even with the less sensitive SE sequence. These transponders consist of a ferrite core surrounded by a solenoid, which makes them incompatible with MRI. It was determined that the transponders of the two 
pony mares used were still legible after MRI and were therefore not destroyed.

\section{Discussion}

We showed here that the transponder used for the mandatory identification of horses within the European Union creates a significant artifact on MRI images, thus preventing the correct visualization of the brain behind the pineal-hypothalamic axis. One solution to avoid this problem is to use alternative imaging strategies, including the use of advanced imaging techniques such as VAT (view angle tilting)-SEMAC (slice encoding metal artefact) and MAVRIC (multiacquisition variable-resonance image combination) $[15,16]$. Such approaches are certainly very effective in the reduction of metal artifacts, but they do not suppress them completely.

Another solution could be to retrieve the chip. However, there is the need of a precise localization of the chip in order to extract it surgically. Here, we used a chip reader that allows an approximate location of the chip within a rectangular area of approximately $20 \mathrm{~cm}$ by $10 \mathrm{~cm}$. We were able to physically locate the chip just $15 \mathrm{~cm}$ below the ear of the horse, which corresponds to the placement of the transponder by a veterinarian. However, this localization was insufficiently precise to extract it through surgery. In this area, we also tried to locate the cyst induced by the chip with ultrasound. For that purpose, we employed an ultrasound scanner (EXAPad from ECAP®) with a $5 \mathrm{~Hz}$ linear probe. The transponder was apparently too small or could not be detected by ultrasound. However, the use of an X-ray scanner or fluoroscopy would indicate the location of the transponder, and it could be possible to surgically extract the chip in an only slightly injurious manner. 
2015//262, the transponder has to be inserted in the middle of the neck. Further studies should be made to investigate a correctly placed transponder and the susceptibility-induced artifact with $3 \mathrm{~T}$ magnets in ponies. In conclusion, caution should be taken to be sure of the implantation location of the transponder; this location should be far enough from the brain (therefore strictly following the EU recommendation) to avoid problems when performing brain MRI under clinical examination or for scientific purposes.

\section{List of abbreviations:}

MRI: Magnetic resonance imaging

\section{Conflict of interests:}

The authors declare that they have no competing interests.

\section{Authors contributions:}

$\mathrm{AE}$ and HA drove the MRI and corrected the final manuscript. GG drove the gas anesthesia and the cardiac monitoring. IL and CD are equine specialized veterinarian and followed the horse from the beginning of anesthesia to waking up. HA is responsible of the MRI. FR took care of the ponies and prepared them for the anesthesia. MK supervised the work, worked on animal experimentation and prepared the manuscript. DG supervised the work, worked on animal experimentation, and prepared the manuscript.

\section{Acknowledgements:}

The authors wish to thank the staff of the UEPAO (T. Blard, P. Barrière, T. Gascogne, Y. Gaude, F. Stieau, J.M. Yvon) for taking care of the horses and for their help during experiments. 
217 Funding:

218 This work was supported by the "Institut Français du Cheval et de l'Equitation" (IFCE). 219 


\section{References :}

[1] Arencibia A, Vazquez JM, Ramirez JA, Ramirez G, Vilar JM, Rivero MA, Alayon S, Gil F. Magnetic resonance imaging of the normal equine brain. Vet. Radiol. Ultrasound 2001; 42, 405-409.

[2] Chaffin MK, Magnetic resonance imaging of the brain of normal neonatal foals. Vet. Radiol. Ultrasound 1997; 38, 2, 102-111.

[3] Dixon J, Lam R, Weller R, Manso-Diaz G, Smith M, Piercy RJ. Clinical application of multidetector CT and MRI for evaluation of cranial nerves in horses in comparison with high resolution imaging standards. Equine Vet. Educ. 2017; 7, 376-384.

[4] Stuckenschneider K, Hellige M, Feige K, Gasse H. 3-Tesla magnetic resonance imaging of the equine brain in healthy horses. Pferdeheilkunde 2014; 6, 657-670.

[5] Kimberlin L, Zur Linden A, Ruoff L. Atlas of clinical imaging and anatomy of the equine head 2016; John Wiley \& Sons.

[6] Vazquez JM, Rivero M, Gil F, Ramirez G, Vilar JM, Arencibia. Magnetic resonance imaging of two normal equine brains and their associated structures. Vet. Rec. 2001; 148(8):229-232.

[7] Audigié F, Tapprest J, George C, Didierlaurent D, Foucher N, Faurie F, Houssin M, Denoix JM. Magnetic resonance imaging of a brain abcess in a 10-months-old filly. Vet. Radiol. Ultrasound 2004; 45, 3, 210-215.

[8] Cavalleri JM, Metzger J, Hellige M, Lampe V, Stuckenschneider K, Tipold A, Beineke A, Becker K, Distl O, Feige K. Morphometric magnetic resonance imaging and genetic testing in cerebellar abiotrophy in Arabian horses. BMC Vet. Res. 2013; 9:105.

[9] Sanders SG, Tucker RL, Bagley RS, Gavin P. Magnetic Resonance imaging features of equine nigropallidal encephalomalacia. Vet. Radiol. Ultrasound. 2005; 42(4):291-296.

[10] Manso-Diaz G, Dyson SJ, Dennis R, Garcia-Lopez JM, Biggi M, Garcia Real MI, San Roman F, Taeymans O. Magnetic resonance imaging characteristics of equine head disorders: 84 cases (2000-2013). Vet. Radiol. Ultrasound 2015; 56, 2, 176-187.

[11] Aurich C. Reproductive cycles of horses. Anim. Reprod. Sci., 124(3-4): 220-228.

[12] Lansade L, Marchand AR, Coutureau E, Ballé C, Polli F, Calandreau L. Personality and predisposition to form habit behaviours during instrumental conditioning in horses (Equuq caballus). PLos One 2017; 12(2): e0171010.

[13] Lansade L, Valenchon M, Foury A, Neveux C, Cole SW, Layé S, Cardinaud B, Lévy F, Moisan MP. Behavioral and Transcriptomic Fingerprints of an Enriched Environment in Horses (Equus caballus). PLoS One. 2014 Dec 10;9(12):e114384

[14] Saito M, Ono S, Kayanuma H, Honnami M, Muto M, Une Y. Evaluation of the susceptibility artifacts and tissue injury caused by implanted microchips in dogs on $1.5 \mathrm{~T}$ magnetic resonance imaging. J. Vet. Med. Sci. 2010; 72, 5, 575-581.

[15] Jungmann PM, Ganter C, Schaeffeler C, Bauer JS, Baum T, Meier RM, Nittka M, Pohlig F, Rechl H, von Eisenhart-rothe R, Rummeny EJ, Woertler K. View angle tilting and sliceendcoding metal artefact correction for artefact reduction in MRI: experimental sequence optimization for orthopaedic tumor endoprotheses ans clinical application. PLos One2015; 10(4): e0124922.

[16] Filli L, Jud L, Luechinger R, Nanz D, Andreisek G, Runge VM, Kozerke S, FarshadAmacker NA. Material dependent implant artefact reduction using SEMAC-VAT and MAVRIC: a prospective MRI Phantom study. Invest. Radiol., 2017; 52(6), 381-387. 


\section{Figure captions:}

Figure 1: On the left, the image of a para-sagittal section of the mare brain showing the impact of the transponder, destroying the images of the cerebellum and the spinal cord and affecting the gray levels of hypothalamus. On the right, images of frontal cuts at the indicated levels from 1 to 4 .

Figure 2: Horizontal 2D T1 SE image of horse head. The effect of the transponder can be observed even with a poorly inducing artefact sequence.

Figure 3: Individual 3D reconstruction of the equine brain. We can notice the deformation induced by the transponder at the back of the brain (white arrows) which prevents analysis on the posterior regions (trunk, cerebellum, occipital lobe). 
Figure 1: Equine Brain Magnetic Resonance Imaging with T1W MPRAGE sequence

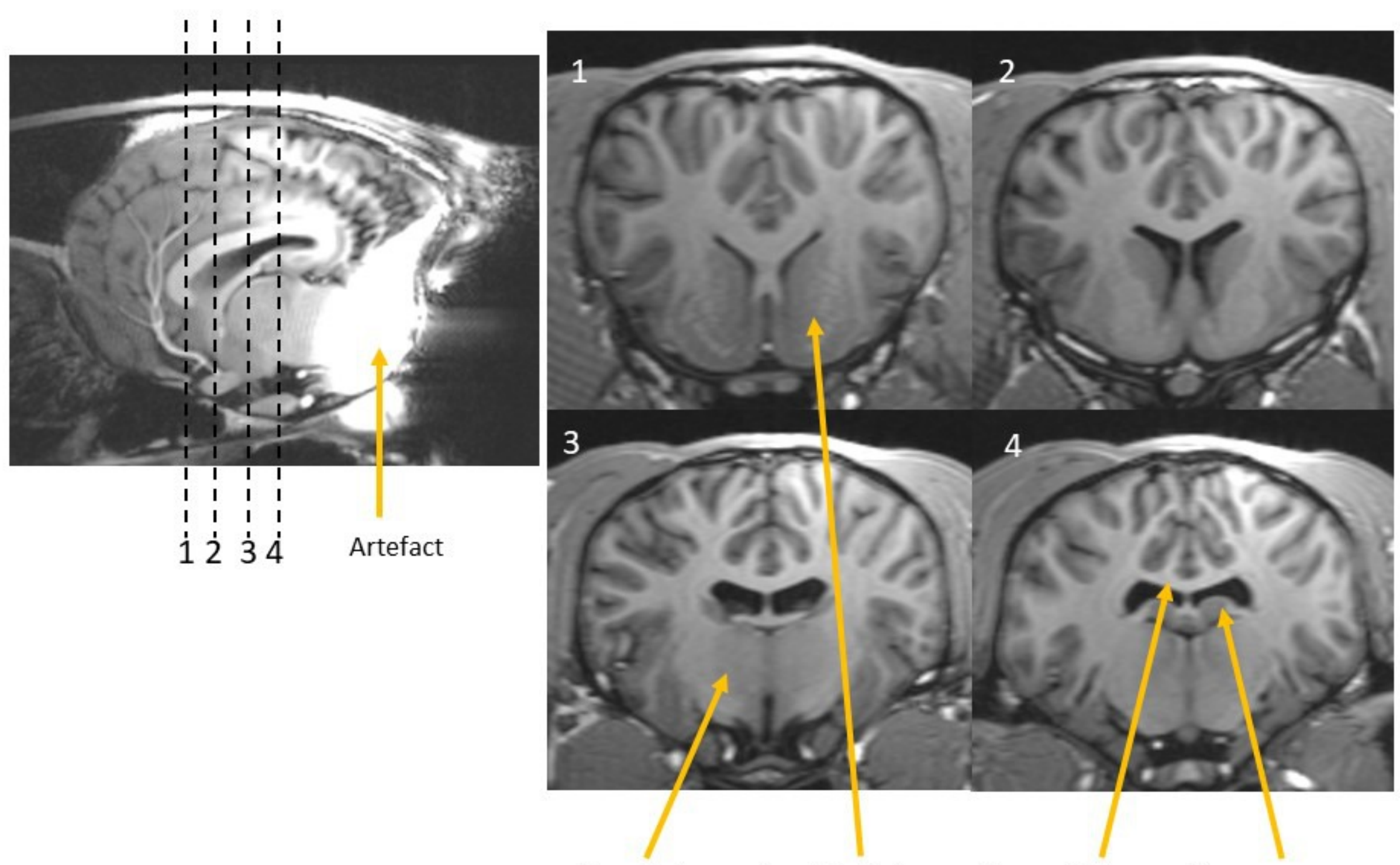

Hypothalamus Caudate-Putamen Corpus Callosum Hippocampus 
Figure 2 In vivo artefact induced by the transponder

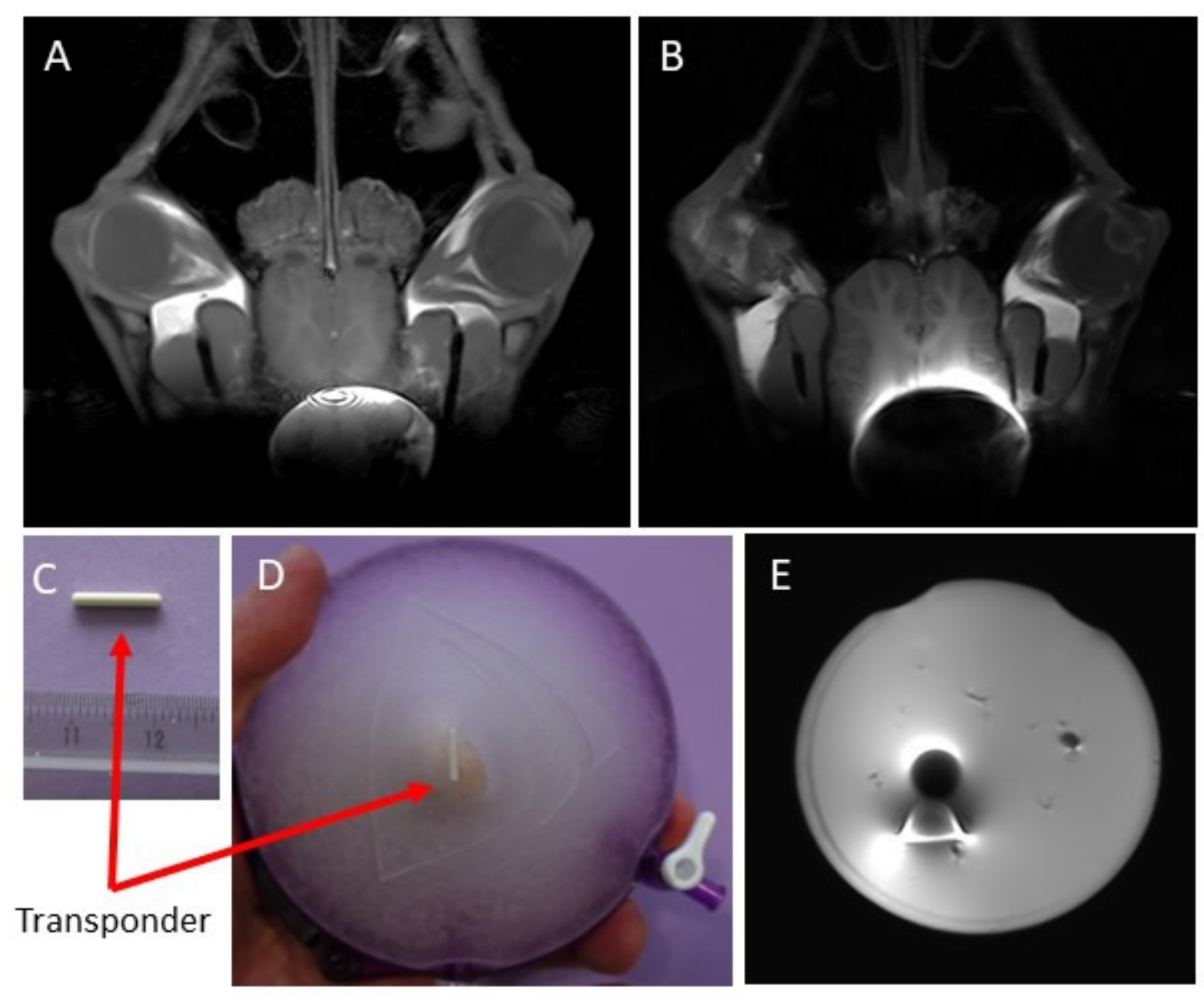


Figure 3: 3-dimensional reconstruction of the brain of one mare

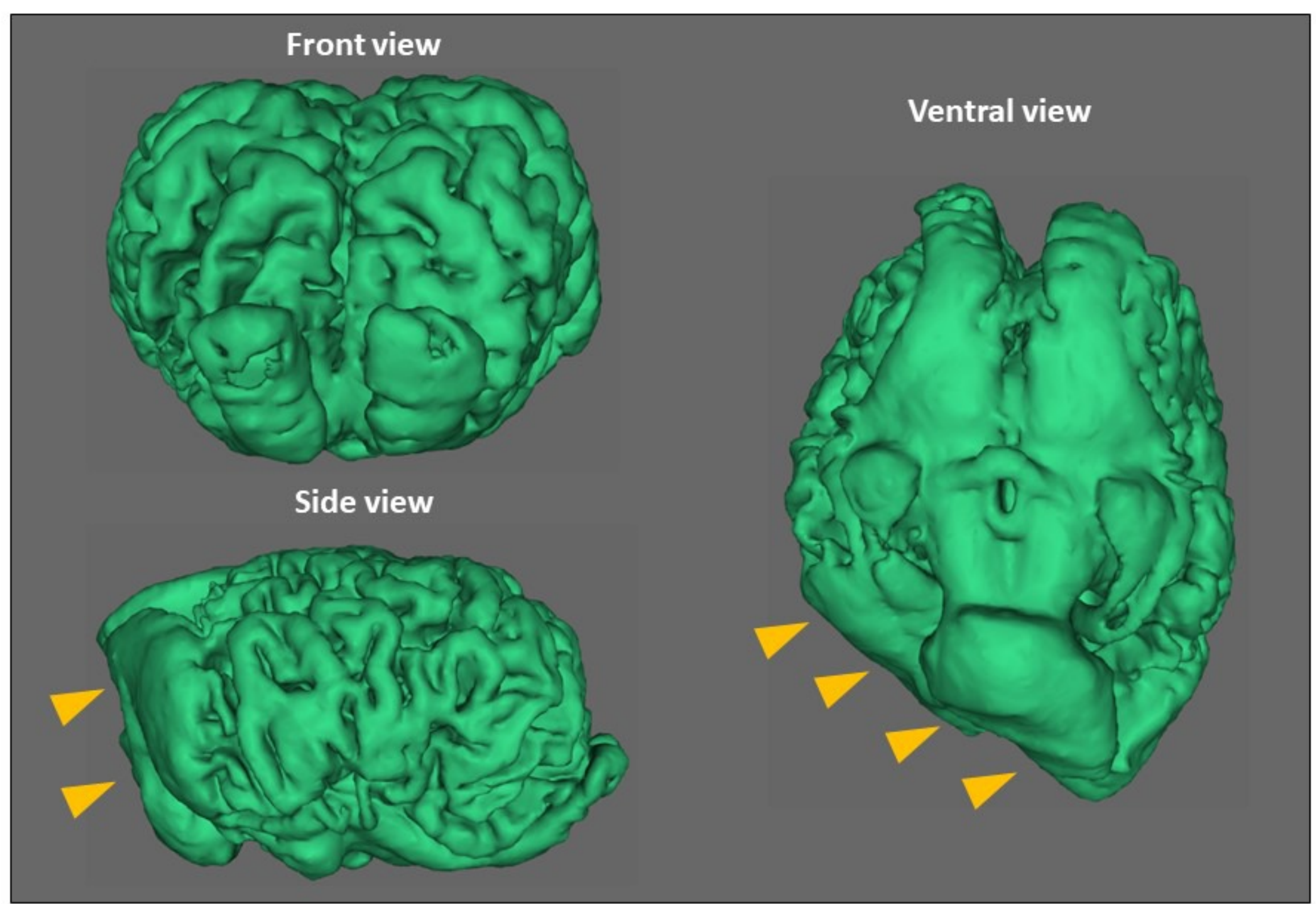

